\title{
Long non-coding RNA MIAT knockdown potentiates the therapeutic effect of transcatheter arterial embolization in liver cancer by regulating the miR-203a/HIF-1 $\alpha$ axis
}

\author{
JIAN LIU, GUANGSHAO CAO, JIANWEN LIU, XIAOYANG ZHAO and HUICUN CAO
}

Department of Intervention, Henan Provincial People's Hospital, Zhengzhou, Henan 450003, P.R. China

Received October 9, 2019; Accepted March 31, 2020

DOI: $10.3892 /$ or.2020.7618

\begin{abstract}
Transcatheter arterial embolization (TAE) and transcatheter arterial chemoembolization (TACE) are often used for palliative treatment of liver cancer. TAE and TACE can induce severe hypoxia. The present study investigated the effect of the myocardial infarction associated transcript (MIAT)/microRNA (miR)-203a/hypoxia-inducible factor 1- $\alpha$ (HIF-1 $\alpha$ ) axis on the therapeutic activity of TAE for liver cancer using hypoxia-treated liver cancer cells and rat orthotopic liver tumors. MIAT, miR-203a and HIF-1 $\alpha$ mRNA levels were assessed by reverse transcription-quantitative PCR assay. The protein expression of HIF-1 $\alpha, \mathrm{Ki}-67$ and vascular endothelial growth factor was determined by western blot assay. The proliferative, migratory and invasive potential of cells was assessed by CCK-8, Transwell migration and invasion assays, respectively. The association between MIAT, miR-203a and HIF- $1 \alpha$ was investigated through bioinformatics analysis, luciferase reporter assay, RNA immunoprecipitation and RNA pull-down assay. In vivo experiments were performed to explore the effect of TAE alone or in combination with MIAT knockdown on the growth of rat liver tumors. The results revealed that MIAT and HIF-1 $\alpha$ were highly expressed, and miR-203a was lowly expressed in liver tumors of patients with liver cancer after TACE treatment and hypoxia-stimulated liver cancer cells. MIAT sequestered miR-203a from its target HIF-1 $\alpha$. MIAT knockdown, miR-203a overexpression or HIF-1 $\alpha$ loss inhibited proliferation, migration and invasion in hypoxia-treated liver cancer cells. MIAT knockdown enhanced TAE-mediated antitumor effects by upregulating miR-203a and downregulating HIF-1 $\alpha$ in rat liver tumors. In conclusion, MIAT knockdown potentiated the therapeutic effect of TAE in liver cancer by regulating the miR-203a/HIF- $1 \alpha$ axis in vitro
\end{abstract}

Correspondence to: Dr Huicun Cao, Department of Intervention, Henan Provincial People's Hospital, 7 Weiwu Road, Jinshui, Zhengzhou, Henan 450003, P.R. China

E-mail: caohuicun2016@163.com

Key words: myocardial infarction associated transcript, microRNA-203a, hypoxia-inducible factor $1-\alpha$, hepatocellular carcinoma, transcatheter arterial embolization and in vivo, thus expanding our understanding on the function and molecular basis of MIAT in TAE treatment for liver cancer.

\section{Introduction}

Liver cancer poses an enormous global threat to human health and life, accounting for approximately $4.7 \%$ of all new cancer cases and $8.2 \%$ of all cancer-related deaths in 2018 in the world (1). Asia and Africa are high-risk liver cancer areas, with $>50 \%$ of new liver cancer cases and deaths occurring in China $(1,2)$. Liver cancer is often diagnosed at the advanced stage and its prognosis is also poor (3). Liver cancer can be cured through surgical resection, liver transplantation and radiofrequency ablation when the disease is diagnosed at the early stage, whereas current therapeutic strategies can only hinder disease progression and extend the length of life for patients with intermediate and advanced liver cancer $(3,4)$. Transcatheter arterial embolization (TAE) and transcatheter arterial chemoembolization (TACE) are often used for the treatment of liver cancer, including palliative treatments for patients with unresectable intermediate and advanced liver cancer, and preoperative treatments for resectable liver cancer $(5,6)$. Hypoxia, a common phenomenon in the majority of malignant tumors, has a positive or negative influence on cancer progression and therapeutic responses depending on duration, environment and severity $(7,8)$. Severe hypoxia leads to cell death, while an oxygen level $>0.5 \%$ inhibits cell death (9).

Long non-coding RNAs (lncRNAs), a group of long ( $>200$ nucleotides) transcripts without protein-coding potential, and microRNAs (miRNAs or miRs), a class of short ( 20 nucleotides) transcripts lacking protein-coding potential, have been identified as vital regulators of gene expression and crucial players in the tumorigenesis and progression of cancers such as liver cancer $(10,11)$. Emerging evidence shows that ncRNAs, including lncRNAs and miRNAs, play vital roles in hypoxia-regulated cancer processes, including tumor invasion and metastasis $(12,13)$. The lncRNA myocardial infarction associated transcript (MIAT) has been revealed to be implicated in the pathogenesis of multiple diseases, including myocardial infarction, diabetic retinopathy and schizophrenia $(14,15)$. Previous studies revealed that MIAT functioned as an oncogenic factor in various cancer types 
such as liver cancer (16-18). Additionally, MIAT was involved in the regulation of hypoxia responses. For instance, MIAT knockdown enhanced the detrimental effect of hypoxia on cell viability, and promoted cell apoptosis induced by hypoxia in rat retinal ganglion cells and retinal Müller cells (19). TACE can induce severe hypoxia, which leads to the alteration of the tumor microenvironment and biological responses (20). Therefore, the roles and molecular basis of MIAT in TACE treatment for liver cancer were further investigated in hypoxia-treated liver cancer cells and rat liver tumors in the present study.

Bioinformatics prediction analysis revealed that MIAT had a probability to bind to miR-203a, and that hypoxia-inducible factor $1-\alpha(\mathrm{HIF}-1 \alpha)$ was a potential target of miR-203a, which has been reported to be a tumor suppressor in multiple cancers, including gastric (21), nasopharyngeal (22) and liver cancer (23). Moreover, miR-203a overexpression led to a notable downregulation of HIF-1 $\alpha$ in glioblastoma cells (24). HIF-1 $\alpha$ has been well documented as a hypoxia-responsive factor in cancers $(25,26)$. Additionally, previous studies revealed that HIF- $1 \alpha$ knockdown curbed tumor angiogenesis and metastasis, and enhanced the TAE-mediated antitumor effect in rat liver tumors (27-29). Consequently, the present study further investigated whether MIAT could exert its crucial function through regulation of the miR-203a/HIF- $1 \alpha$ axis in TACE treatment for liver cancer in hypoxia-treated liver cancer cells and rat liver tumors.

\section{Materials and methods}

Clinical samples and cell culture. Patients with liver cancer (40-50 years old, male) were recruited from Henan Provincial People's Hospital (Zhengzhou, China) from January to May 2017 and divided into a TACE-untreated group $(n=22)$ and a TACE-treated group $(n=20)$. Necrotic parts of liver tumors were excluded from our study. The expression levels of MIAT, miR-203a and HIF-1 $\alpha$ were assessed by reverse transcription-quantitative PCR (RT-qPCR) assay in liver tumors without necrosis.

Patients in the TACE-treated group received $\geq 1$ session of TACE alone without other treatments prior to resection. Patients with liver cancer in the TACE-untreated group did not receive any treatment before surgery. The present experiments were approved by the Research Ethics Committee of Henan Provincial People's Hospital. Written informed consent was obtained from all participants prior to the experiments.

The liver cancer cell line HepG2 (Cell Bank of the Chinese Academy of Sciences) was cultured in Dulbecco's modified Eagle's medium (cat. no. 11965092; Thermo Fisher Scientific, Inc.) supplemented with $10 \%$ fetal bovine serum (cat. no. 16140071; Thermo Fisher Scientific, Inc.) under normoxia $\left(20 \% \mathrm{O}_{2}\right)$ or hypoxia $\left(1 \% \mathrm{O}_{2}, 5 \% \mathrm{CO}_{2}\right)$ conditions at $37^{\circ} \mathrm{C}$. This cell line was derived from a 15 year-old Caucasian male with liver cancer. The cell line was authenticated by STR profiling. The results were as follows: D5S818: 11,12; D13S317: 9,13; D7S820: 10,10; D16S539: 12,12; vWA: 17,17; THO1: 9,9; Amelogenin: XY; TPOX: 8,9; and CSF1PO: 10,11. Normoxia or hypoxia was created using the Anoxomat Mark II Anaerobic system (Mart Microbiology B.V.).
Reagents. Small interference (si)RNAs targeting MIAT (si-MIAT\#1, si-MIAT\#2) and a scramble control (si-NC), as well as siRNA targeting HIF-1 $\alpha$ (si-HIF-1 $\alpha$ ) and its negative control (NC) (si-nc) were obtained from Shanghai GenePharma Co., Ltd. miR-203a mimic (cat. no. miR10000264-1-5) and its NC (miR-NC, cat. no. miR1N0000001-1-5), and miR-203a inhibitor (anti-miR-203a; cat. no. miR20000264-1-5) and its NC (anti-miR-NC; cat. no. miR2N0000001-1-5) were ordered from Guangzhou RiboBio Co., Ltd. The HIF-1 $\alpha$ coding region was cloned into the pcDNA3.1 vector by Shanghai Genomeditech Co., Ltd. to obtain a pcDNA-HIF-1 $\alpha$ overexpression plasmid. The target sequences of si-MIAT\#1 and si-MIAT\#2 were 5'-CCAGGCTCCTTTAAACCAA-3' and 5'-GCAGTTCTTAGCTCATATA-3', respectively. The target sequences of si-HIF-1 $\alpha$ were 5'-GGCCGCTCAATTTATGAA T-3' and 5'-GCTGGAGACACAATCATAT-3'.

Cell transfection. HepG2 cells were transfected with corresponding biotin-labeled miRNAs, biotin-labeled probes, miRNA mimics, miRNA inhibitors, siRNAs or plasmids, and cultured for $24 \mathrm{~h}$ under normoxia or hypoxia conditions. Cell transfection was performed using DharmaFECT 4 reagent (cat. no. T-2004-0X) or DharmaFECT Duo transfection reagent (cat. no. T-2010-03) (both from Thermo Fisher Scientific, Inc.) according to the instructions of the manufacturer.

$R T$ - $q$ PCR assay. Total RNA was isolated from HepG2 cells and liver tumors using TRIzol reagent (cat. no. 15596018; Thermo Fisher Scientific, Inc.) following the protocols of the manufacturer. The miR-203a level was measured using Bulge-Loop miRNA qRT-PCR Starter kit (cat. no. C10211-1; Guangzhou RiboBio Co., Ltd.) and Bulge-Loop miRNA primer sets (cat. no. MQPS0000787-1-100; Guangzhou RiboBio Co., Ltd.) with small nuclear RNA U6 (cat. no. MQPS0000002-1-100; Guangzhou RiboBio Co., Ltd.) as the internal control. cDNA first strand synthesis reaction programs included reverse transcription at $42^{\circ} \mathrm{C}$ for $60 \mathrm{~min}$ and enzyme inactivation at $70^{\circ} \mathrm{C}$ for $10 \mathrm{~min}$. Quantitative PCR reaction programs consisted of pre-denaturation at $95^{\circ} \mathrm{C}$ for $10 \mathrm{~min}$ and 40 cycles of denaturation at $95^{\circ} \mathrm{C}$ for $2 \mathrm{sec}$, annealing at $60^{\circ} \mathrm{C}$ for $20 \mathrm{sec}$ and extension at $70^{\circ} \mathrm{C}$ for $10 \mathrm{sec}$.

For detection of MIAT, HIF-1 $\alpha$ and GAPDH levels, cDNA was synthesized from an RNA template using M-MLV reverse transcriptase (cat. no. 28025021; Thermo Fisher Scientific, Inc.) and quantified using Fast SYBR ${ }^{\mathrm{TM}}$ Green Master mix (cat. no. 4385617; Thermo Fisher Scientific, Inc.). GAPDH functioned as the house-keeping gene to normalize the expression of MIAT and HIF-1 $\alpha$. The primer sequences for MIAT, HIF-1 $\alpha$ and GAPDH were as follows: HIF- $1 \alpha$ forward, 5 '-CCA CCTATGACCTGCTTGGT-3' and reverse, 5'-TGTCCTGTG GTGACTTGTC-3'; MIAT forward, 5'-CAAAGAGCCCTC TGCACTAG-3' and reverse, 5'-ACCTTGGTTACCCCTGTG ATG-3'; and GAPDH forward, 5'-GTCTCCTCTGACTTC AACAGCG-3' and reverse, 5'-ACCACCCTGTTGCTGTAG CCAA-3'. Reverse transcription reaction samples without M-MLV reverse transcriptase and ribonuclease inhibitor were incubated at $65^{\circ} \mathrm{C}$ for $5 \mathrm{~min}$ and then immediately chilled on ice. Next, the reverse transcription reaction was performed at $37^{\circ} \mathrm{C}$ for $50 \mathrm{~min}$ and the reaction was subsequently inactivated at $70^{\circ} \mathrm{C}$ for $15 \mathrm{~min}$. Quantitative PCR reaction programs 
included pre-denaturation at $95^{\circ} \mathrm{C}$ for $5 \mathrm{~min}$ and 40 cycles of denaturation at $95^{\circ} \mathrm{C}$ for $5 \mathrm{sec}$ and annealing/extension at $60^{\circ} \mathrm{C}$ for $30 \mathrm{sec}$. Quantitative PCR reactions were run on Applied Biosystems 7500 Fast Real-Time PCR System (Applied Biosystems; Thermo Fisher Scientific, Inc.). Relative expression patterns of genes were analyzed using the $2^{-\Delta \Delta C T}$ method (30).

Western blot assay. Proteins were extracted from HepG2 cells and liver tumors by centrifugation using RIPA Lysis Buffer (cat. no. P0013E; Beyotime Institute of Biotechnology) containing a protease inhibitor cocktail (cat. no. 5892970001; Roche Diagnostics) and then quantified using Bio-Rad Bradford Protein Assay kit (cat. no. 5000002; Bio-Rad Laboratories, Inc.). Next, $30 \mu$ g protein samples were separated by $10 \%$ SDS-PAGE and transferred to polyvinylidene fluoride membranes (cat. no. IPVH00010; EMD Millipore). Then, the membranes were blocked with 5\% non-fat milk for $1 \mathrm{~h}$ at room temperature and incubated overnight at $4^{\circ} \mathrm{C}$ with primary antibodies against HIF- $1 \alpha$ (product code ab16066; 1:2,000 dilution), Ki-67 (product code ab16667; 1:50 dilution), vascular endothelial growth factor (VEGF; product code ab106580; 1:1,000 dilution) and GAPDH (product code ab181602; 1:5,000 dilution; all from Abcam). Subsequently, the membranes were incubated for $1 \mathrm{~h}$ at room temperature with a horseradish peroxidase-conjugated secondary antibody (product codes ab205718 or ab205719; 1:5,000 dilution; Abcam). Finally, the protein signals were detected using SignalFire ${ }^{\mathrm{TM}}$ ECL Reagent (product no. 6883; Cell Signaling Technology, Inc.) on a Bio-Rad ChemiDoc XRS imaging system (Bio-Rad Laboratories, Inc.) and quantified using Quantity One 1-D Analysis Software (version 4.6.6; Bio-Rad Laboratories, Inc.).

Cell proliferation detection. The cell proliferative capacity was assessed by CCK-8 assay kit (cat. no. CK04-01; Dojindo Molecular Technologies, Inc.) referring to the protocols of the manufacturer. Briefly, cells (50,000 cells/well) transfected with corresponding oligonucleotides or plasmids, alone or in combination, were plated into 96-well plates and maintained under the hypoxia condition for $24 \mathrm{~h}$. Next, $10 \mu \mathrm{l} \mathrm{CCK-8} \mathrm{solu-}$ tion was added into each well and incubated for $3 \mathrm{~h}$. Finally, the absorbance was determined at $450 \mathrm{~nm}$ using a SpectraMax M3 Multi-Mode microplate reader (Molecular Devices, LLC).

Transwell migration and invasion assays. Cell migratory and invasive potential was estimated using 24-well Transwell chambers (cat. no. 3422; Corning Inc.) containing $8.0 \mu \mathrm{m}$ pore filter membrane inserts. For cell invasion assay, the membranes on the chambers were precoated with Matrigel (cat. no. 356234; BD Biosciences). At $24 \mathrm{~h}$ after transfection, the transfected cells $\left(3 \times 10^{4}\right)$ were resuspended into serum-free medium and then added into the upper chambers. Complete medium supplemented with $20 \%$ FBS was added into the lower chambers. After $24 \mathrm{~h}$ of incubation under hypoxia conditions, cells on the upper chambers were removed using a cotton swab. The cells attached on the bottom surface of the membranes were fixed with pre-cold methanol for $20 \mathrm{~min}$ at $4^{\circ} \mathrm{C}$, stained with crystal violet solution $(0.1 \%$; cat. no. V5265; Sigma-Aldrich; Merck KGaA) for $30 \mathrm{~min}$ at room temperature and counted in 5 random fields under a light microscope (magnification x200). The Transwell migration assay was performed following the same procedures as described in the cell invasion assay, i.e., in Transwell chambers, but without Matrigel.

Luciferase reporter assay. Potential interaction between miR-203a and MIAT or HIF-1 $\alpha$ was predicted through miRcode (http://www.mircode.org/) or TargetScan Human7.2 (http://www.targetscan.org/vert_72/), respectively. Partial sequences of MIAT and HIF-1 $\alpha$ 3' untranslated region (UTR) containing the corresponding miR-203a binding sites were cloned into the psiCHECK-2 vector by Hanbio Biotechnology Co., Ltd. to generate MIAT-wild-type (Wt) reporter and HIF-1 $\alpha$-Wt reporter, respectively. MIAT-mutant (Mut) reporter and HIF- $1 \alpha$-Mut reporter were also produced by mutating matching miR-203a complementary sites by Hanbio Biotechnology Co., Ltd. HepG2 cells were co-transfected with MIAT-Wt reporter, MIAT-Mut reporter, HIF-1 $\alpha$-Wt reporter, or HIF-1 $\alpha$-Mut reporter and miR-NC or miR-203a mimic. At $48 \mathrm{~h}$ after transfection, luciferase activities were measured using the Dual-Luciferase Reporter Assay system (cat. no. E1910; Promega Corporation) according to the instructions of the manufacturer.

RNA pull-down assay. An RNA pull-down assay was carried out as previously described (31) to explore whether MIAT could bind to miR-203a through putative binding sites. Biotin-labeled wt miR-203a (Bio-miR-203a), biotin-labeled mutant miR-203a containing mutated MIAT binding sites (Bio-miR-203a-Mut) and their NC (Bio-miR-NC), as well as biotin-labeled wt MIAT probe (Bio-MIAT), biotin-labeled mutant MIAT probe (Bio-MIAT-Mut) and a scramble probe (Bio-NC) were obtained from Sangon Biotech Co., Ltd. HepG2 cells were transfected with matching biotin-labeled miRNAs or probes. After $48 \mathrm{~h}$ of culture, cells were collected and lysed with lysis buffer (20 mM Tris- $\mathrm{HCl}$ (pH 7.5), $100 \mathrm{mM}$ $\mathrm{KCl}, 5 \mathrm{mM} \mathrm{MgCl} 2,0.3 \%$ IGEPAL CA-630 (cat. no. I8896; Sigma-Aldrich) supplemented with protease inhibitor (cat. no. 5892970001; Roche Diagnostics) and RNase inhibitor (cat. no. EO0381; Thermo Fisher Scientific, Inc.). Next, cell lysates were co-incubated overnight at $4^{\circ} \mathrm{C}$ with pre-treated Dynabeads ${ }^{\circledR}$ M-270 Streptavidin (cat. no. 11205D; Thermo Fisher Scientific, Inc.). Subsequently, RNA was isolated and purified from the beads. Finally, MIAT and miR-203a enrichment levels were determined by RT-qPCR assay.

RNA immunoprecipitation (RIP) assay. A RIP assay was carried out in HepG2 cells using the EZ-Magna RIP kit (cat. no. 17-701; EMD Millipore) and anti-argonaute 2 (Ago2; cat. no. 03-110; Part \#CS204386; EMD Millipore; 1:200 dilution) or IgG (cat. no. 03-110; Part \#CS200621; EMD Millipore; 1:200 dilution) antibodies following the instructions of the manufacturer. RNA was isolated and purified from IgG or Ago2 immunoprecipitation complexes. MIAT and miR-203a levels were assessed by RT-qPCR assay.

Animal experiments. Adult male Wistar rats (200-220 g) were obtained from the Laboratory Animal Center of Zhengzhou University and housed in a pathogen-free environment with a temperature of $22 \pm 2^{\circ} \mathrm{C}$ and a relative humidity of $50 \pm 5 \%$ under 

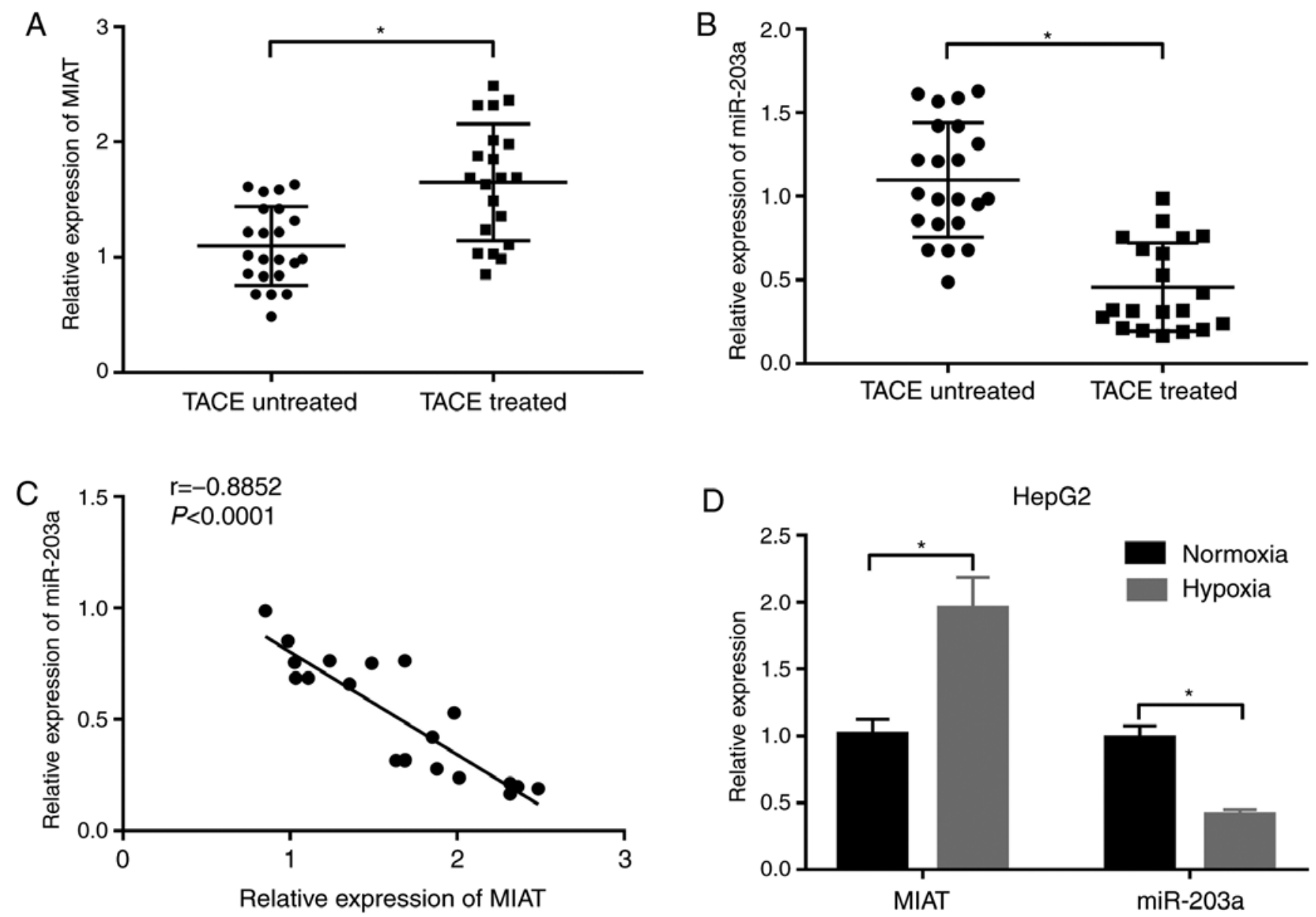

Figure 1. MIAT is highly expressed and miR-203a is lowly expressed in patients with liver cancer after TACE treatment and hypoxia-stimulated liver cancer cells. (A) MIAT and (B) miR-203a levels were assessed by RT-qPCR assay in the liver tumors of 20 patients with liver cancer who underwent TACE treatment and 22 patients with liver cancer without TACE treatment. (C) Correlation analysis of MIAT and miR-203a expression in the liver tumors of 20 patients with liver cancer who underwent TACE treatment. (D) HepG2 cells were cultured for $24 \mathrm{~h}$ under hypoxic or normoxic conditions, followed by assessment of MIAT and miR-203a expression levels via RT-qPCR assay. "P<0.05. RT-qPCR, reverse transcription-quantitative PCR; miR, microRNA; MIAT, myocardial infarction associated transcript; TACE, transcatheter arterial embolization.

light-dark cycles (12 h light/dark). In addition, food and water were provided ad libitum. Animal experiments were performed with the approval of the Animal Ethics Committee of Henan Provincial People's Hospital and the procedures for the Care and Use of Laboratory Animals in cancer research. Sustained short hairpin RNA against MIAT (sh-MIAT) and a scramble control (sh-NC) were obtained from Hanbio Biotechnology Co., Ltd. In this study, a total of 60 rats were used in the animal experiments. Rat liver cancer cells $\left(10^{6}\right.$ cells $/ 0.1 \mathrm{ml}$ of normal saline) infected with or without sh-NC or sh-MIAT lentiviruses were injected into the fascia under the neck skin of rats (10 rats in each group). All rats were euthanized using intraperitoneal phenobarbital injection (100 mg/kg; Guangdong Bangmin Pharmaceutical Co., Ltd.) at 14 days after injection (experimental animals are euthanized when they are dying or obsolete due to various factors or they have fulfilled the tasks of experiments). After breathing arrest, tumors with a size of $\sim 1 \mathrm{~cm}^{3}$ were harvested. Then, fresh tumors $(\sim 1 \mathrm{~mm}$ in diameter $)$ without tumor capsules and necrotic tissues were implanted into the livers of rats as previously described (32). On day 14 after tumor transplantation $\left(\sim 1 \mathrm{~cm}^{3}\right.$ in tumor volume), TAE was performed following previously described procedures $(32,33)$. The NC, TAE+sh-NC, and TAE+sh-MIAT groups contained
10 rats prior to tumor transplantation. However, 2 rats after sham or TAE treatment in NC, 1 rat after TAE+sh-NC treatment, and 1 rat after TAE+sh-MIAT treatment, were revealed to be dead. These deaths may have been caused by anaesthetization, surgery or liver cancer. Five rats in the NC, TAE+sh-NC, or TAE+sh-MIAT groups were euthanized and tumors were resected 2 weeks later, and the tumor volumes were measured using the formula: $\mathrm{V}=0.5 \mathrm{x} \mathrm{L}$ (longest tumor diameter) $\mathrm{x} \mathrm{S}$ (shortest tumor diameter) x $\mathrm{S}$ (shortest tumor diameter). The expression levels of MIAT, miR-203a, HIF-1 $\alpha$ and VEGF were measured by RT-qPCR and western blot assay in non-necrotic liver tumors. Animal health and behavior were monitored every 3 days post-surgery.

Hematoxylin and eosin $(H \& E)$ staining. H\&E staining of liver tumor tissues was performed 2 weeks after TAE. In brief, formaldehyde-fixed tumor tissues were embedded in paraffin. Thereafter, the sections $(5 \mu \mathrm{m})$ were dewaxed with xylene, hydrated with gradient ethanol solutions, rinsed with water and stained with hematoxylin staining solution for $10 \mathrm{~min}$ and eosin staining solution for $2 \mathrm{~min}$ at room temperature. Images of the tissue sections were obtained using an optical microscope (magnification x200). 
A

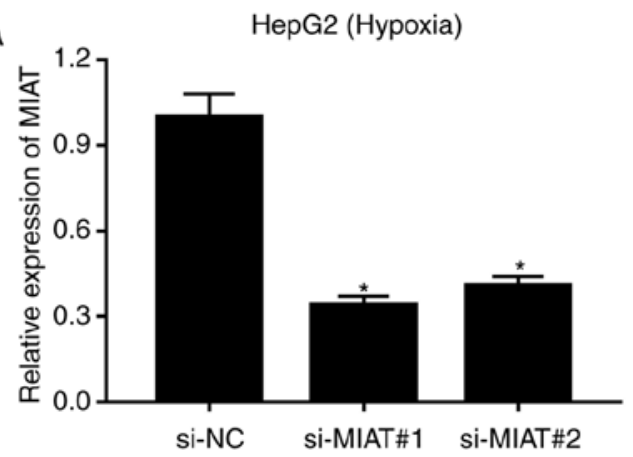

C

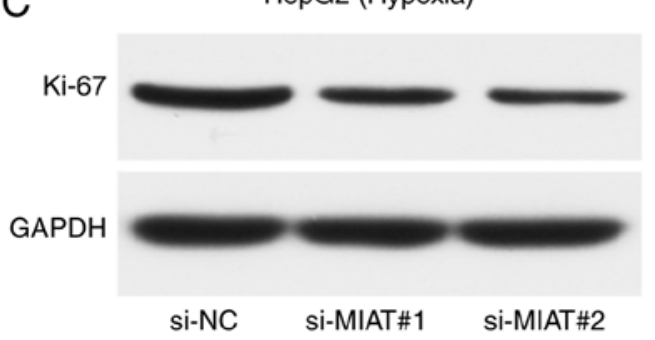

D

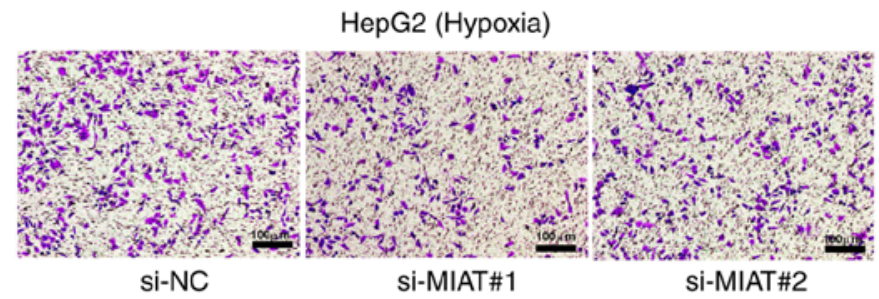

E

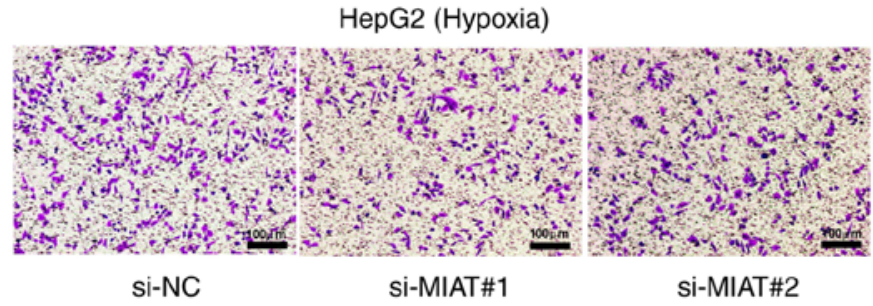

B
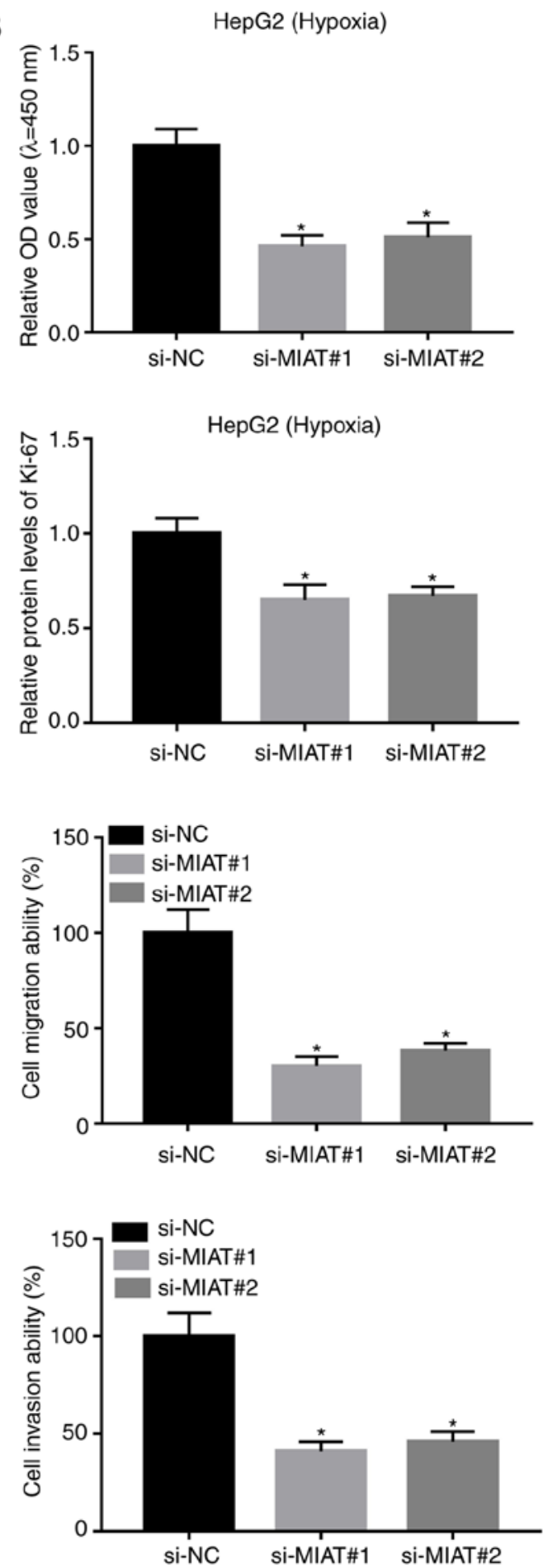

Figure 2. MIAT knockdown suppresses proliferation, migration and invasion in hypoxia-stimulated HepG2 cells. (A-E) HepG2 cells transfected with si-NC, si-MIAT\#1 or si-MIAT\#2 were cultured under hypoxic conditions for $24 \mathrm{~h}$. (A) The expression level of MIAT was assessed by RT-qPCR assay. (B) Cell proliferative potential was determined by CCK-8 assay. (C) Protein levels of Ki-67 were detected by western blot assay. (D) Cell migratory and (E) invasive capacities were assessed by Transwell migration and invasion assays. " $\mathrm{P}<0.05$. MIAT, myocardial infarction associated transcript; RT-qPCR, reverse transcription-quantitative PCR; si, small interference; NC, negative control.

Statistical analysis. Data were obtained from $>3$ independent experiments and analyzed with GraphPad Prism 7 software (GraphPad Software, Inc.). Analysis of differences between groups was conducted using Student's t-test (2-groups data) or one-way ANOVA with Tukey's post hoc test. ( $>2$-groups data). $\mathrm{P}<0.05$ was considered to indicate a statistically significant difference.

\section{Results}

MIAT is highly expressed and miR-203a is lowly expressed in liver tumors of patients with liver cancer with TACE treatment and hypoxia-stimulated liver cancer cells. Clinical data revealed that the MIAT level was notably upregulated and miR-203a expression was markedly downregulated in the liver 


\section{A Target location chr22:27070723-27070729}
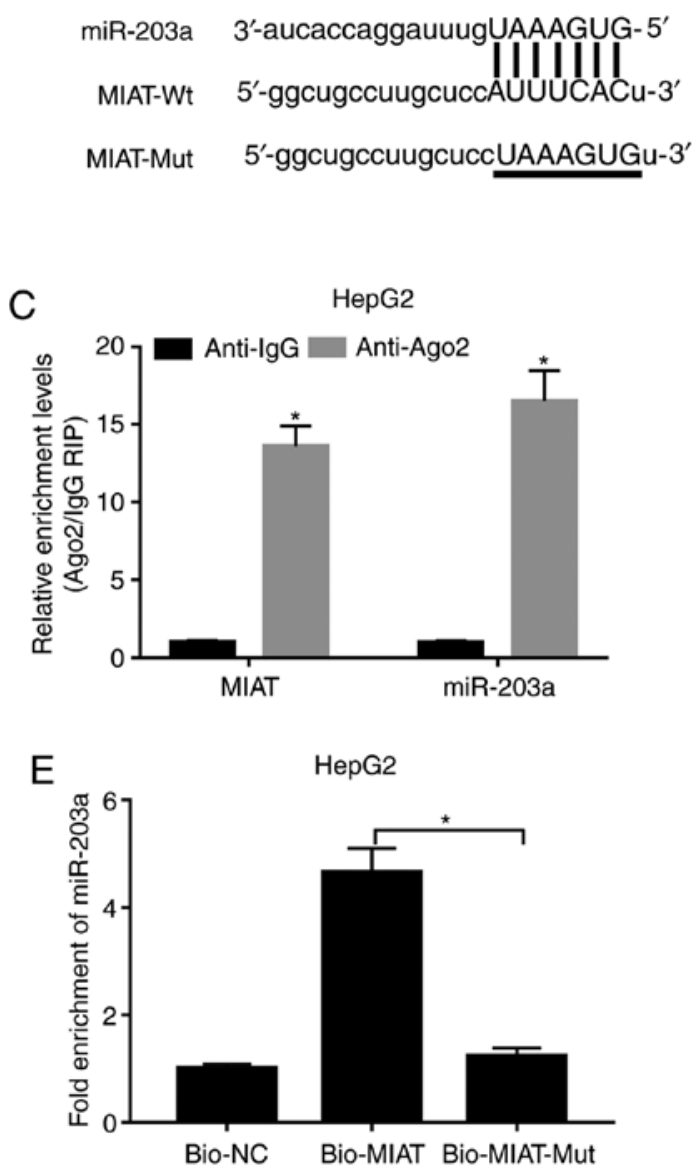

B

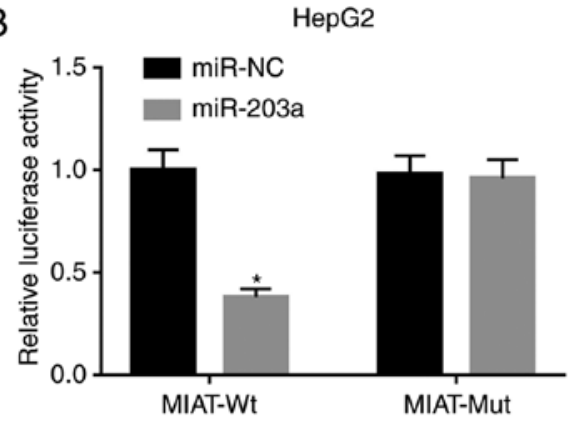

D
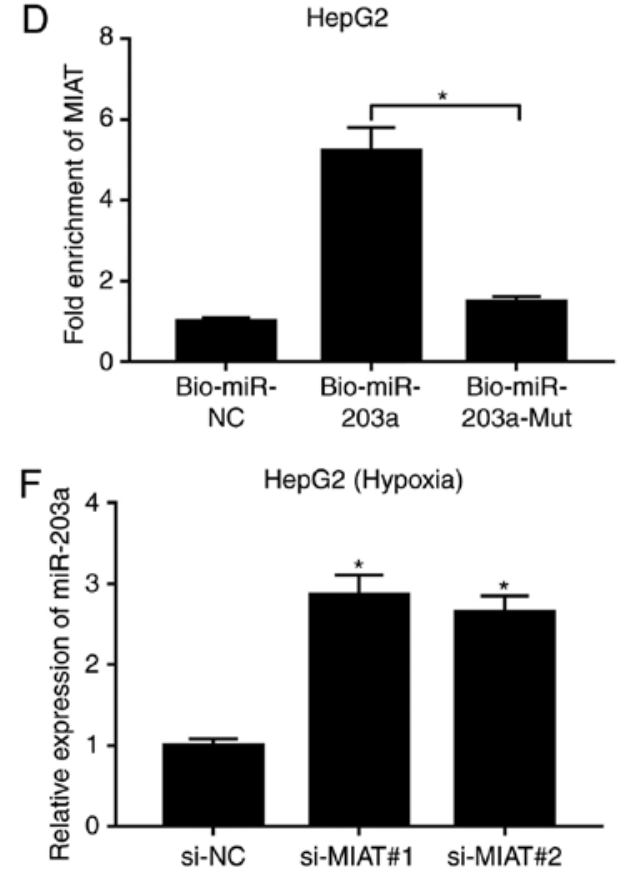

Figure 3. MIAT knockdown induces miR-203a expression by direct interaction. (A) Predicted binding sites between MIAT and miR-203a by miRcode and mutant sites in MIAT-Mut reporter. (B) HepG2 cells were co-transfected with miR-NC or miR-203a and MIAT-Wt or MIAT-Mut reporter, followed by detection of luciferase activities at $48 \mathrm{~h}$ after transfection. (C) The enrichment degree of MIAT and miR-203a in IgG or Ago2 immunoprecipitation complex was assessed by RNA immunoprecipitation and RT-qPCR assays. (D) HepG2 cells were transfected with Bio-miR-NC, Bio-miR-203a or Bio-miR-203a-Mut. At $48 \mathrm{~h}$ post-transfection, the MIAT level pulled down by the above biotin-labeled miRNAs was assessed by RNA pull-down and RT-qPCR assays. (E) HepG2 cells were transfected with Bio-NC, Bio-MIAT or Bio-MIAT-Mut. After $48 \mathrm{~h}$ of incubation, miR-203a level enriched by these biotin-labeled probes was detected through RNA pull-down and RT-qPCR assays. (F) HepG2 cells transfected with si-NC, si-MIAT\#1 or si-MIAT\#2 were exposed to hypoxic conditions for $24 \mathrm{~h}$. Then, the expression level of miR-203a was assessed by RT-qPCR assay. ${ }^{*} \mathrm{P}<0.05$. MIAT, myocardial infarction associated transcript; si, small interference; miR, microRNA; RT-qPCR, reverse transcription-quantitative PCR; wt, wild type; mut, mutant; Ago2, argonaute 2; NC, negative control; Bio, biotin.

tumors of 20 patients with liver cancer who underwent TACE treatment compared with 22 patients with liver cancer without TACE treatment (Fig. 1A and B). Moreover, the miR-203a level was negatively associated with the MIAT level in the liver tumors of 20 patients with liver cancer who underwent TACE treatment (Fig. 1C). Consistently, higher MIAT expression and lower miR-203a expression were observed in HepG2 cells under hypoxia conditions compared with cells under normoxia conditions (Fig. 1D). These data indicated that MIAT and miR-203a may play vital roles in TACE treatment for liver cancer.

MIAT knockdown suppresses proliferation, migration and invasion in hypoxia-stimulated HepG2 cells. Next, si-MIAT\#1, si-MIAT\#2 and a scramble control (si-NC) were synthesized to evaluate the effect of MIAT loss on the proliferative, migratory and invasive capacities of HepG2 cells under hypoxic conditions. Firstly, transfection efficiency analysis revealed that the transfection of si-MIAT\#1 or si-MIAT\#2 could significantly reduce the expression level of MIAT in hypoxia-treated HepG 2 cells compared with cells transfected with si-NC (Fig. 2A). A CCK-8 assay revealed that MIAT depletion inhibited proliferation in HepG2 cells under hypoxic conditions (Fig. 2B). The present results also demonstrated that the expression of proliferative markers such as Ki-67 was markedly decreased in hypoxia-exposed HepG2 cells following MIAT knockdown (Fig. 2C). Moreover, MIAT loss led to a noticeable reduction in the migratory and invasive abilities of HepG2 cells exposed to hypoxic conditions (Fig. 2D and E).

MIAT knockdown induces miR-203a expression by direct interaction. Subsequently, bioinformatics analysis indicated that MIAT could interact with miR-203a (Fig. 3A). To further demonstrate this prediction, MIAT-Wt reporter containing wt 
A

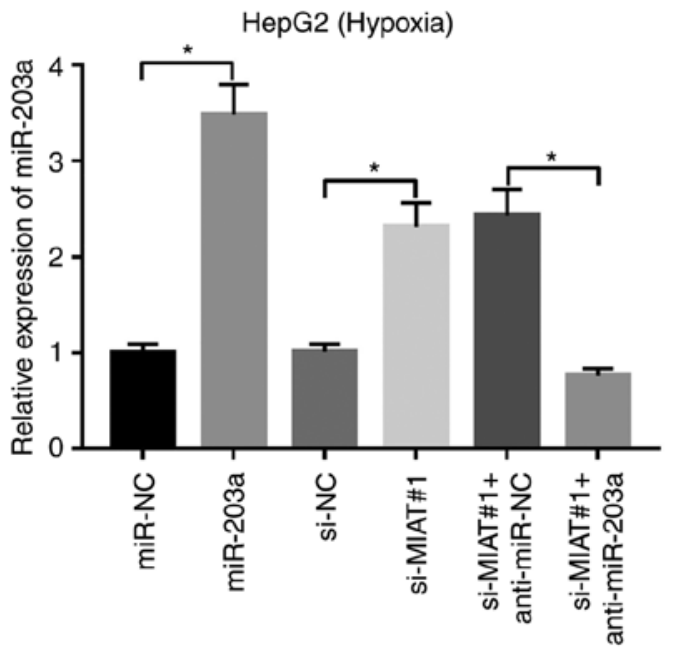

C

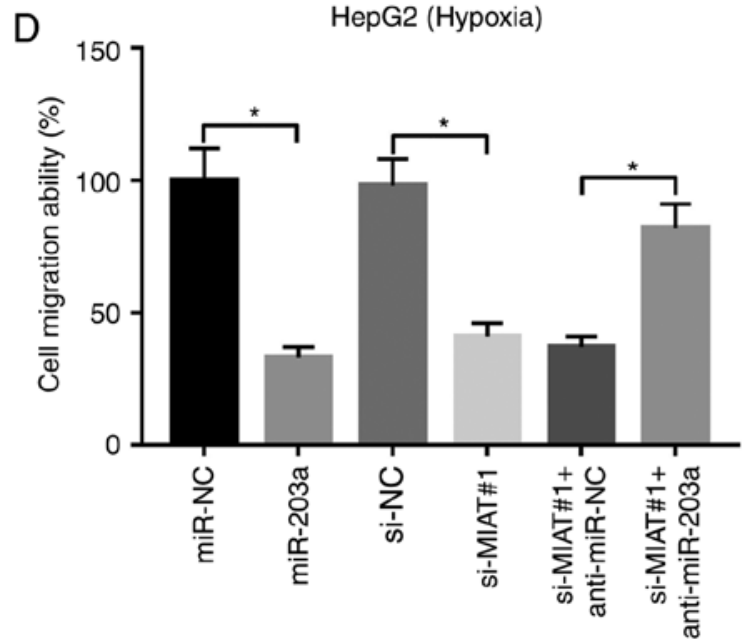

B
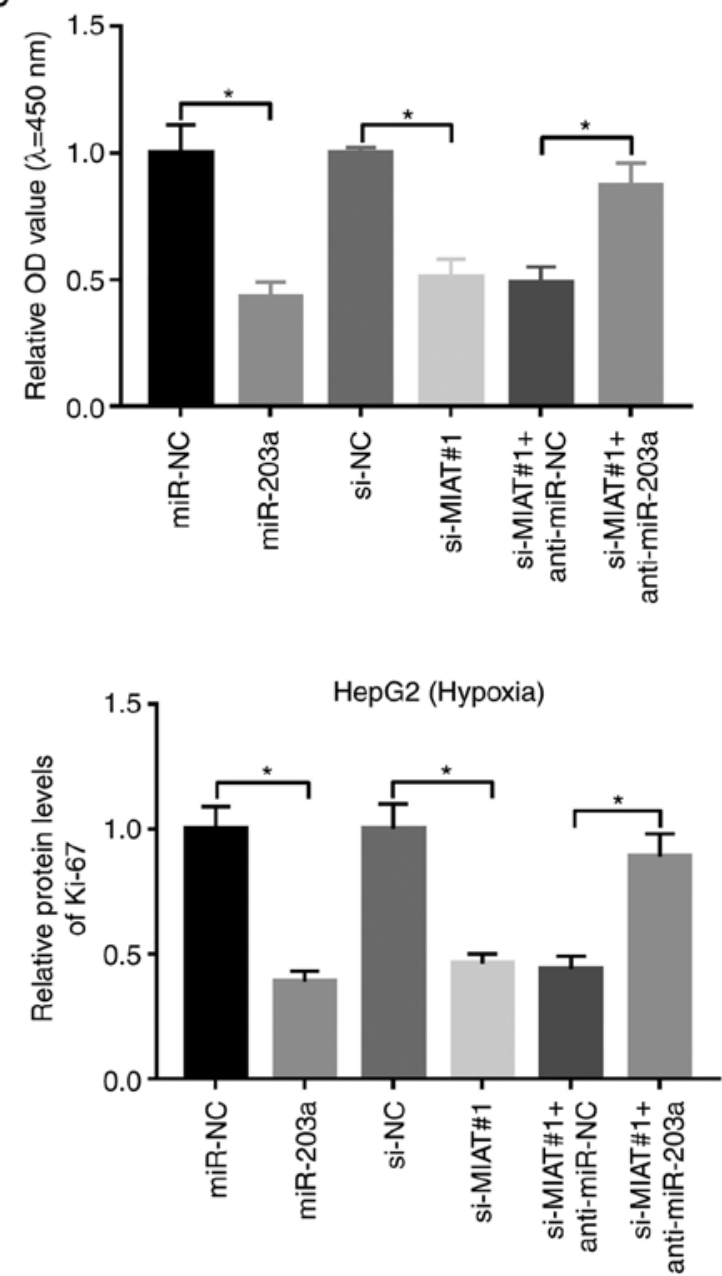

E

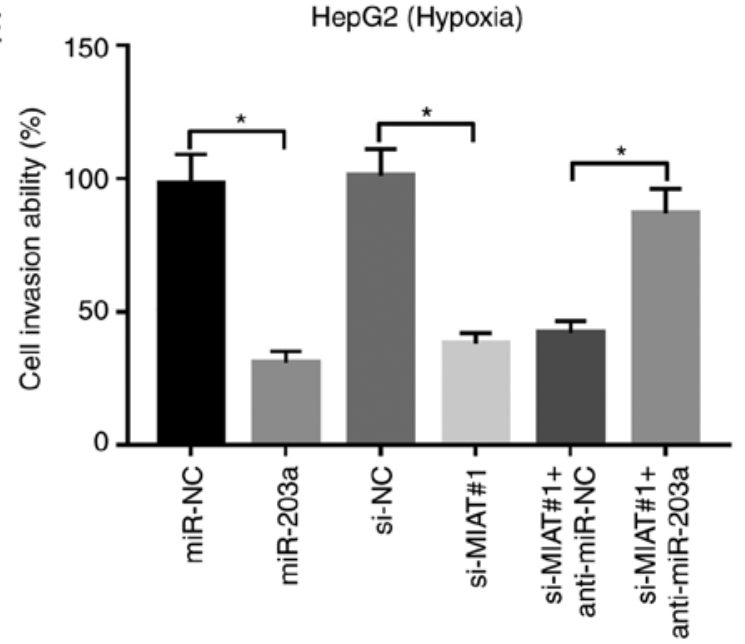

Figure 4. Downregulation of miR-203a weakens the detrimental effects of MIAT knockdown on the proliferation, migration and invasion of HepG2 cells under hypoxic conditions. (A-E) HepG2 cells transfected with miR-NC, miR-203a, si-NC, si-MIAT\#1, si-MIAT\#1 + anti-miR-NC or si-MIAT\#1 + anti-miR-203a were cultured under hypoxic conditions for $24 \mathrm{~h}$. (A) The expression level of miR-203a was assessed by RT-qPCR assay. (B) Cell proliferative ability was assessed by CCK-8 assay. (C) The protein levels of Ki-67 were determined by western blot assay. (D) Cell migratory and (E) invasive capacities were determined by Transwell migration and invasion assays. "P<0.05. MIAT, myocardial infarction associated transcript; si, small interference; miR, microRNA; NC, negative control; RT-qPCR, reverse transcription-quantitative PCR.

miR-203a binding sites and MIAT-Mut reporter containing mutant miR-203a binding sites were constructed. Following luciferase reporter assay, the results revealed that miR-203a overexpression led to a significant downregulation of luciferase activity of the MIAT-Wt reporter, but did not have a marked effect on the luciferase activity of the MIAT-Mut reporter (Fig. 3B). Ago2, a core component of the RNA-induced silencing complex, plays vital roles in miRNA-mediated gene 
A Position $1141-1147$ of HIF-1 $\alpha$ 3'UTR

miR-203a ${ }^{3}$-gAucAccAggAuuUgUAAAGUg- 5'

HIF-1 $\alpha$-Mut 5' -cUuuUuuUcaUguAgUAAAGUa-3'
$\mathrm{B}$

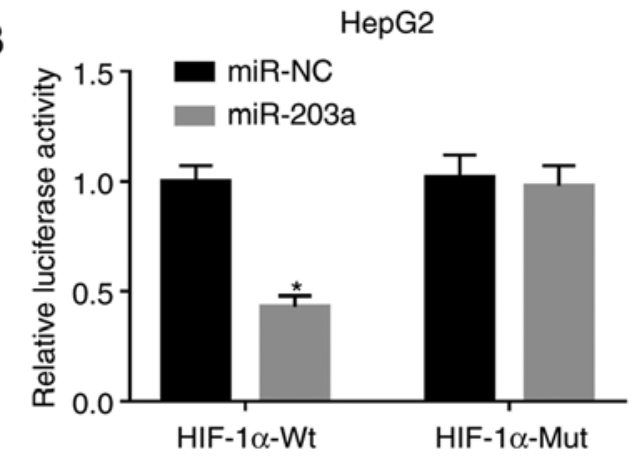

D

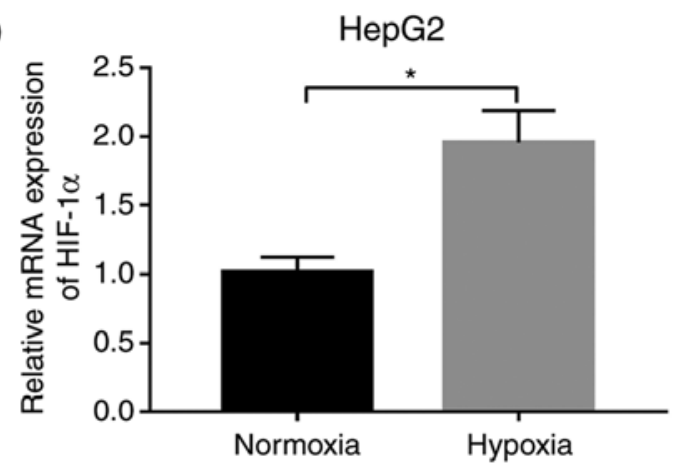

$\mathrm{F}$

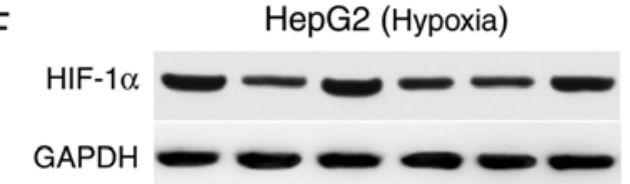

$\mathrm{E}$ HepG2 (Hypoxia)

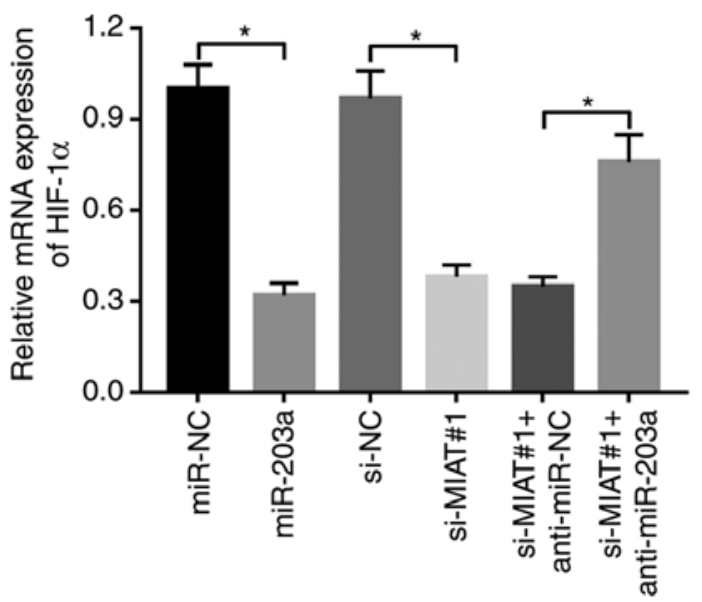

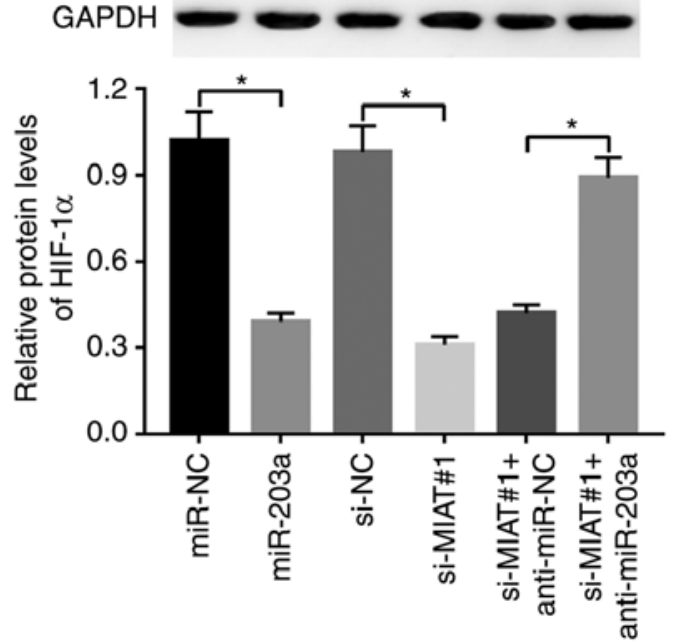

Figure 5. HIF-1 $\alpha$ is a downstream target of the MIAT/miR-203a axis. (A) Putative complementary sites between miR-203a and HIF-1 $\alpha$ 3'-untranslated region by TargetScan prediction website and mutant sites in HIF-1 $\alpha$-Mut reporter. (B) The effect of miR-203a overexpression or no overexpression on the luciferase activities of HIF-1 $\alpha$-Wt or HIF-1 $\alpha$-Mut reporter was detected by luciferase reporter assay at $48 \mathrm{~h}$ after transfection in HepG2 cells. (C) The mRNA level of HIF-1 $\alpha$ was assessed by RT-qPCR assay in liver tumors of patients with liver cancer with or without TACE treatment, and (D) HepG2 cells under normoxic or hypoxic conditions. HepG2 cells transfected with miR-NC, miR-203a, si-NC, si-MIAT\#1, si-MIAT\#1 + anti-miR-NC or si-MIAT\#1 + anti-miR-203a were cultured under hypoxic conditions for $24 \mathrm{~h}$. Next, (E) mRNA and (F) protein levels of HIF-1 $\alpha$ were detected by RT-qPCR and western blot assays, respectively. "P<0.05. MIAT, myocardial infarction associated transcript; miR, microRNA; HIF-1 $\alpha$, hypoxia-inducible factor $1-\alpha$; Mut, mutant; RT-qPCR, reverse transcription-quantitative PCR; si, small interference; NC, negative control.

silencing. Hence, a RIP assay was performed using an anti-Ago2 antibody in HepG2 cells to explore whether MIAT could bind miR-203a. The results revealed that MIAT and miR-203a were significantly enriched in the anti-Ago2 group (Fig. 3C), indicating a possible interaction between MIAT and miR-203a in HepG2 cells. Moreover, RNA pull-down assay revealed that MIAT was significantly enriched by Bio-miR-203a but not by Bio-miR-203a-Mut (Fig. 3D). Similarly, Bio-MIAT could pull down abundant miR-203a in HepG2 cells, while Bio-MIAT-Mut had little enrichment effect on miR-203a (Fig. 3E). In summary, these outcomes revealed that MIAT could directly bind to miR-203a in HepG2 cells. Next, it was further demonstrated that MIAT loss mediated by si-MIAT\#1 or si-MIAT\#2 led to a notable increase in the expression level 
A
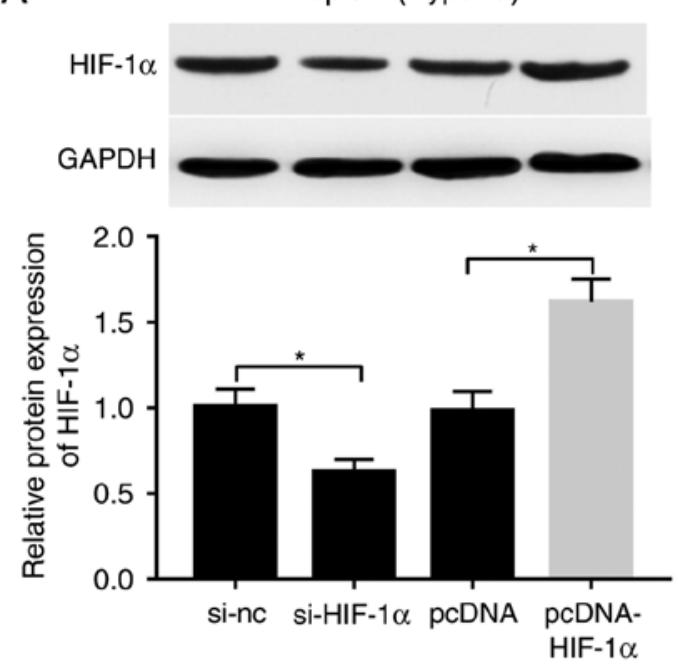

C
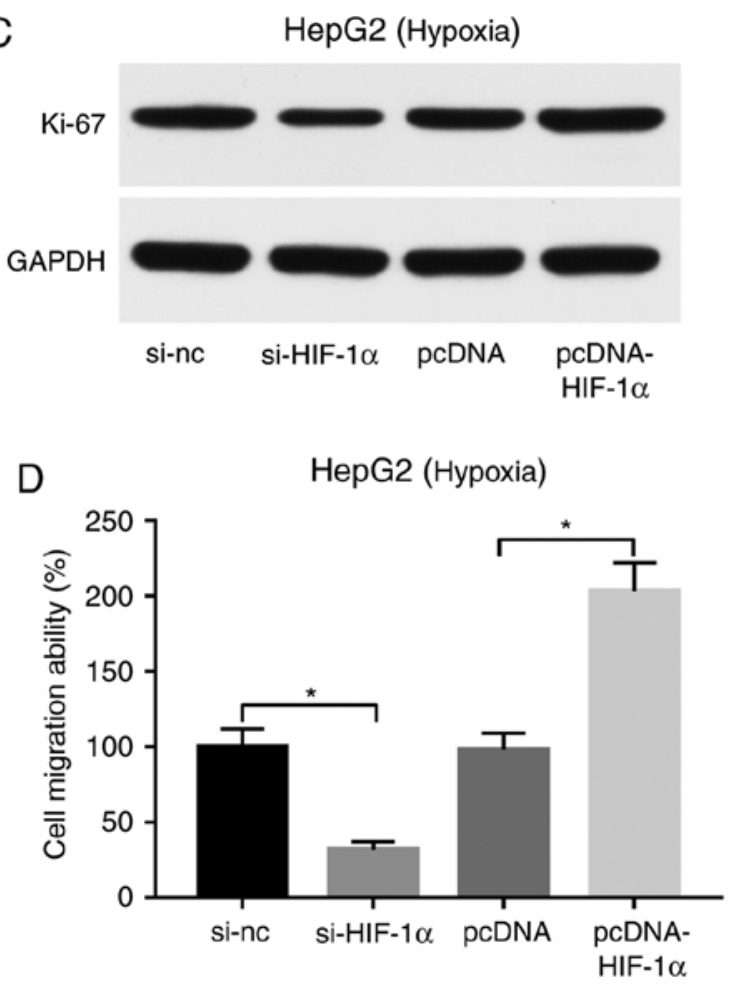
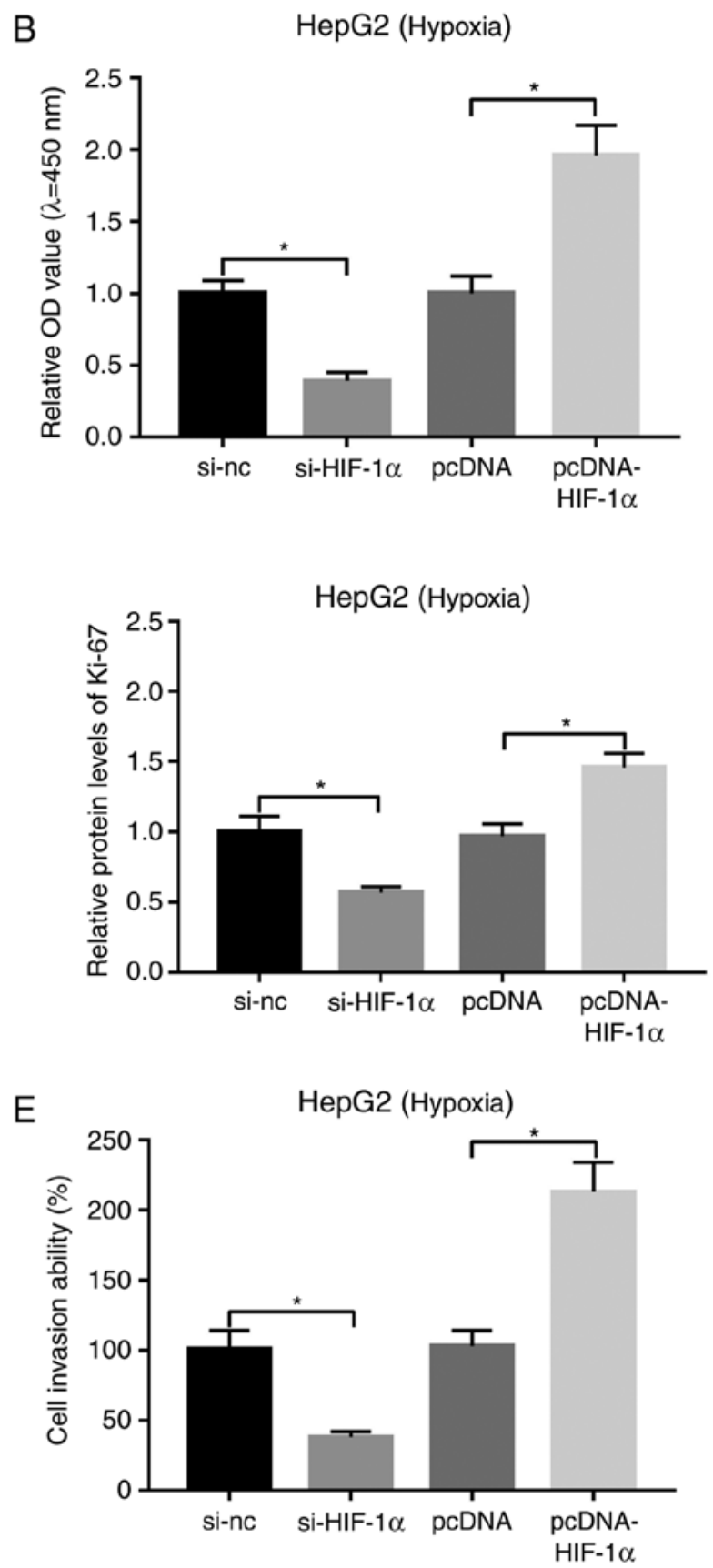

Figure 6. Effect of HIF-1 $\alpha$ knockdown or overexpression on proliferation, migration and invasion of hypoxia-treated HepG2 cells. (A-E) HepG2 cells transfected with si-NC, si-HIF-1 $\alpha$, pcDNA or pcDNA-HIF-1 $\alpha$ were cultured under hypoxic conditions for $24 \mathrm{~h}$, followed by the assessment of (A) HIF-1 $\alpha$ protein level, (B) cell proliferative ability, (C) Ki-67 protein expression, (D) cell migratory and (E) invasive capacities. "P<0.05. HIF-1 $\alpha$, hypoxia-inducible factor $1-\alpha$; si, small interference; NC, negative control.

of miR-203a in HepG2 cells exposed to hypoxic conditions (Fig. 3F).

Downregulation of miR-203a weakens the detrimental effects of MIAT knockdown on proliferation, migration and invasion of HepG2 cells under hypoxic conditions. Next, an RT-qPCR assay validated that the transfection of miR-203a mimic led to a marked increase in the expression level of miR-203a, and the addition of anti-miR-203a inhibited the increase in the expression level of miR-203a induced by
MIAT knockdown in HepG2 cells under hypoxic conditions (Fig. 4A). Furthermore, miR-203a overexpression decreased cell proliferation (Fig. 4B), inhibited the expression of proliferative markers such as Ki-67 (Fig. 4C), and decreased cell migratory and invasive abilities in HepG2 cells under hypoxic conditions (Fig. 4D and E). Moreover, it was further demonstrated that miR-203a loss weakened the detrimental effects of MIAT knockdown on the proliferation, migration and invasion of HepG2 cells under hypoxic conditions (Fig. 4B-E). 
A
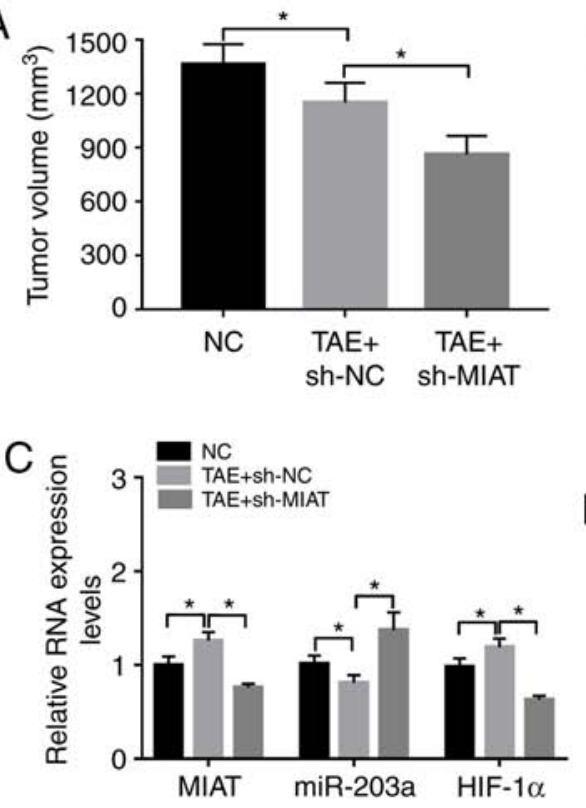

B
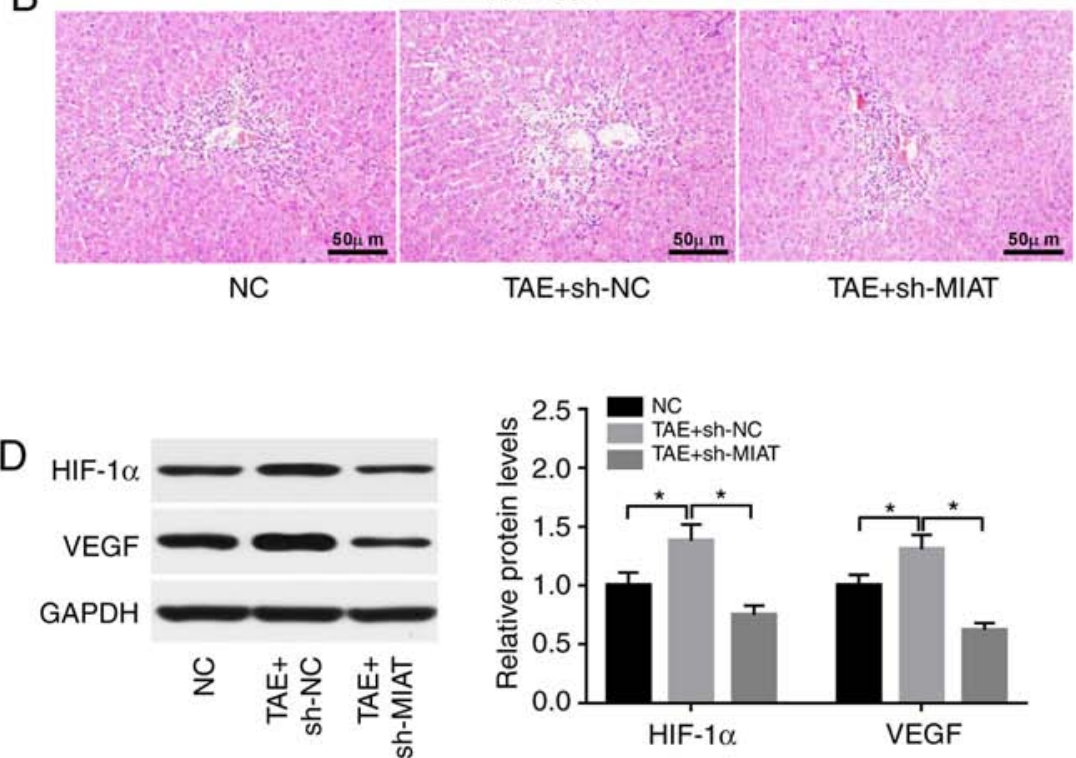

HE 200x

TAE+sh-NC

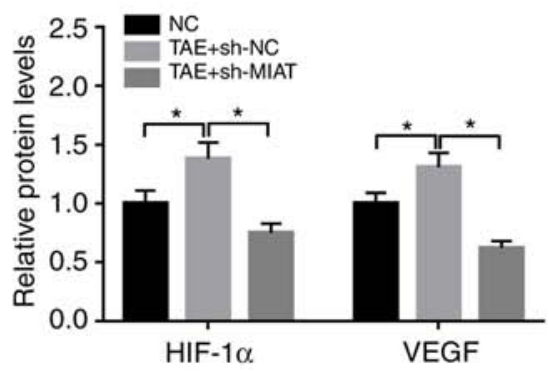

Figure 7. MIAT knockdown enhances TAE-mediated antitumor effect by upregulating miR-203a and downregulating HIF-1 $\alpha$ in rat liver tumors. (A) The effect of TAE alone or in combination with MIAT loss on the volume of rat liver tumors was measured 3 weeks after TAE treatment. The maximum diameter of tumors was 16.1, 14.4 and $12.6 \mathrm{~mm}$ in the NC, TAE+sh-NC, and TAE+sh-MIAT groups, respectively. The maximum volume of tumors was 1502,1298 or $986 \mathrm{~mm}^{3}$ in the NC, TAE+sh-NC, and TAE+sh-MIAT groups, respectively. (B) H\&E staining of liver tumor tissues. (C) MIAT, microRNA-203a and HIF-1a mRNA levels were determined by RT-qPCR assay in rat liver tumors of the sham (NC), TAE and TAE treatment + MIAT loss groups. (D) Protein levels of HIF-1 $\alpha$ and VEGF were detected by western blot assay in rat liver tumors of the sham (NC), TAE and TAE treatment + MIAT loss groups. "P<0.05. MIAT, myocardial infarction associated transcript; TAE, transcatheter arterial embolization; HIF-1 $\alpha$, hypoxia-inducible factor 1- $\alpha$; H\&E, hematoxylin and eosin; RT-qPCR, reverse transcription-quantitative PCR; VEGF, vascular endothelial growth factor; NC, negative control.

HIF-1 $\alpha$ is a downstream target of the MIAT/miR-203a axis. Prediction results revealed the existence of some complementary bases between HIF-1 $\alpha$ 3'UTR and miR-203a (Fig. 5A), indicating that HIF- $1 \alpha$ is a potential target of miR-203a. The results of luciferase reporter assay revealed that miR-203a overexpression led to a significant decrease in the luciferase activity of the HIF-1 $\alpha$-Wt reporter, while miR-203a upregulation did not have a marked effect on the luciferase activity of the HIF-1 $\alpha$-Mut reporter, which contains mutant miR-203a binding sites (Fig. 5B), suggesting that miR-203a could directly bind to HIF-1 $\alpha$ 3'UTR via putative binding sites. In addition, the present study demonstrated that the expression level of HIF-1 $\alpha$ was significantly increased in the liver tumors of 20 patients with liver cancer who underwent TACE treatment compared with the 22 patients with liver cancer without TACE treatment (Fig. 5C). Consistently, higher HIF-1 $\alpha$ expression was observed in HepG2 cells under hypoxic conditions than in cells under normoxic conditions (Fig. 5D). Moreover, RT-qPCR and western blot assays revealed that miR-203a overexpression or MIAT knockdown led to a significant reduction in HIF-1 $\alpha$ mRNA and protein levels in hypoxia-treated HepG2 cells (Fig. 5E and F). miR-203 loss weakened the inhibitory effect of MIAT knockdown on HIF-1 $\alpha$ mRNA and protein expression in hypoxia-stimulated HepG2 cells (Fig. 5E and F).

Effects of HIF-1 $\alpha$ knockdown and overexpression on the proliferation, migration and invasion of Hep $\mathrm{G} 2$ cells under hypoxic conditions. si-HIF- $1 \alpha$ and pcDNA-HIF- $1 \alpha$ overexpression plasmid were synthesized to further explore HIF-1 $\alpha$ function in liver cancer. A western blot assay demonstrated that the addition of si-HIF- $1 \alpha$ effectively triggered a reduction in the expression level of HIF-1 $\alpha$ in hypoxia-treated HepG2 cells (Fig. 6A). Conversely, transfection of pcDNA-HIF-1 $\alpha$ led to a significant increase in the protein expression level of HIF-1 $\alpha$ in hypoxia-stimulated HepG2 cells (Fig. 6A). Subsequent loss-of-function analysis revealed that depletion of HIF-1 $\alpha$ decreased cell proliferation (Fig. 6B), migration (Fig. 6D) and invasion (Fig. 6E), and suppressed Ki-67 expression (Fig. 6C) in hypoxia-treated HepG2 cells. Conversely, enforced expression of HIF-1 $\alpha$ induced cell proliferation (Fig. 6B), migration (Fig. 6D) and invasion (Fig. 6E), and increased Ki-67 expression levels (Fig. 6C) in hypoxia-stimulated HepG2 cells.

MIAT knockdown enhances TAE-mediated antitumor effects by upregulating miR-203a and downregulating HIF-l $\alpha$ in rat liver tumors. The present study demonstrated that TAE inhibited the growth of rat liver tumors and MIAT knockdown enhanced the TAE-mediated antitumor effect in rat liver tumors (Fig. 7A). Lack of MIAT led to markedly fewer blood vessels (Fig. 7B). Moreover, TAE treatment led to a significant increase in MIAT and HIF-1 $\alpha$ mRNA levels, and a significant reduction in the expression level of miR-203a in rat liver tumors (Fig. 7C). Furthermore, the MIAT and HIF-1 $\alpha$ mRNA levels were significantly reduced, while the expression level of miR-203a was significantly increased, in TAE-treated rat liver tumors following MIAT knockdown (Fig. 7C). In addition, the protein levels of HIF- $1 \alpha$ and VEGF were significantly increased in TAE-treated rat liver tumors compared with untreated tumors (Fig. 7C). Moreover, MIAT knockdown inhibited the increase in HIF-1 $\alpha$ and VEGF protein levels induced by TAE in rat liver tumors (Fig. 7D) 


\section{Discussion}

Although surgical resection or liver transplantation is the principal therapeutic strategy for patients with liver cancer, only a fraction of patients at the early stage are suitable for these treatment options $(34,35)$. Recently, TAE and TACE have emerged as effective locoregional therapies for each stage of patients with liver cancer, especially for those with unresectable liver cancer $(35,36)$. Compared with surgical resection or liver transplantation, TAE and TACE have advantages such as lesser trauma, slight pain and rapid recovery. In comparison with chemotherapy, TACE can deliver higher doses of chemotherapeutic drugs to specific tissues with reduced systemic drug toxicity $(37,38)$.

The present study demonstrated that MIAT and HIF-1 $\alpha$ were highly expressed, while miR-203a was lowly expressed, in liver tumors of patients with liver cancer who underwent TACE treatment and in liver cancer cells upon hypoxia treatment. MIAT expression was negatively associated with miR-203a expression in liver tumor samples of patients with liver cancer who underwent TACE treatment. MIAT could directly bind to miR-203a, and HIF-1 $\alpha$ was a direct target of miR-203a. Moreover, MIAT positively regulated HIF-1 $\alpha$ expression via miR-203a in hypoxia-treated liver cancer cells. Functional analysis revealed that MIAT knockdown, miR-203a overexpression or HIF-1 $\alpha$ silencing suppressed cell proliferation, migration and invasion in hypoxia-exposed liver cancer cells. Conversely, HIF-1 $\alpha$ overexpression exerted the opposite function. Moreover, miR-203a downregulation alleviated the detrimental effects of MIAT loss on proliferation, migration and invasion in liver cancer cells under hypoxic conditions. Additionally, MIAT knockdown enhanced TACE-mediated antitumor effects by increasing miR-203a, and reducing HIF- $1 \alpha$ and VEGF in rat liver tumors.

Prior studies revealed that MIAT knockdown could hinder tumorigenesis and progression of liver cancer. For example, MIAT-associated genes were greatly enriched in EMT-linked pathways, and MIAT knockdown promoted epithelial marker E-cadherin expression, inhibited mesenchymal marker $\mathrm{N}$-cadherin expression, and blocked cell migration and invasion in liver cancer (39). MIAT loss weakened the proliferative and invasive abilities of liver cancer cells and hindered liver cancer xenograft tumor growth by negatively regulating miR-214 (40). The present data revealed that MIAT loss impaired cell proliferative, migratory and invasive potential in hypoxia-stimulated liver cancer cells, and potentiated TACE-mediated antitumor effects in rat liver tumors.

Following luciferase reporter assay, RIP and RNA pull-down assays demonstrated that MIAT could directly bind to miR-203a, and MIAT knockdown led to an increase in miR-203 expression in liver cancer cells. Enforced expression of miR-203a suppressed cell proliferation, migration and invasion, while miR-203a downregulation mitigated the inhibitory effects of MIAT knockdown on cell proliferation, migration and invasion in hypoxia-treated liver cancer cells.

miR-203a has been revealed to be a tumor-suppressive miRNA in liver cancer. For instance, miR-203a overexpression inhibited cell proliferation, hampered cell cycle progression and promoted cell apoptosis in liver cancer cells (Huh7 and Hep3B) (41). Ectopic expression of miR-203a suppressed proliferation, migration and invasion by targeting BCAT1 in HepG2 cells (42).

Subsequent experiments demonstrated that HIF-1 $\alpha$ was a target of miR-203a. MIAT functioned as a molecular sponge of miR-203a to sequester miR-203a from its target HIF-1 $\alpha$. HIF-1, which is composed of HIF- $1 \alpha$ and HIF-1 $\beta$ subunits, has been revealed to induce the expression of hypoxia-responsive genes, which are implicated in various cancer-related biological events such as proliferation, angiogenesis and metastasis (38). HIF-1 $\alpha$ is easily degraded by the proteasome under normoxic conditions, whereas HIF- $1 \alpha$ is stabilized and dimerizes with HIF-1 $\beta$ under hypoxic conditions (43). A previous study indicated that the effect of HIF-1 on the proliferation and apoptosis of liver cancer cells was controversial (43). A prior study revealed that HIF-1 improved the invasive and migratory potential of liver cancer cells by inducing EMT under hypoxic conditions (44). Consistent with the outcomes of this study (44), our results demonstrated that HIF-1 $\alpha$ overexpression promoted cell proliferation, migration and invasion in hypoxia-treated liver cancer cells. Additionally, the present study revealed that TAE treatment led to a notable upregulation of MIAT and HIF-1 $\alpha$ expression, and a marked downregulation of miR-203a in rat liver tumors. In line with our results, Chen et al reported that the expression level of HIF-1 $\alpha$ was notably upregulated in hypoxia-treated liver cancer cells, and TAE led to a marked increase in the expression level of HIF-1 $\alpha$ in rat liver tumors (27).

Previous studies revealed that MIAT could facilitate the development and progression of liver cancer by sponging miR-214 (45) and miR-22-3p (46). Moreover, miR-3662 (47), miR-338-3p (48) and miR-199a (49) inhibited liver cancer tumorigenesis and progression by directly targeting HIF- $1 \alpha$. These studies indicated that the aforementioned miRNAs may have potential competitive effects with miR-203a.

Collectively, the present data revealed that MIAT knockdown decreased liver cancer cell proliferation, migration and invasion under hypoxic conditions and, potentiated TACE-mediated antitumor effects in rat liver tumors by regulating the miR-203a/HIF-1 $\alpha$ axis, thus elucidating the vital roles of MIAT and miR-203a in TACE treatment for liver cancer, and identifying a novel and key regulatory pathway (MIAT/miR-203a/HIF-1 $\alpha$ ) in hypoxia-associated responses and TACE treatment for liver cancer.

\section{Acknowledgements}

Not applicable.

\section{Funding}

No funding was received from the government or organizations.

\section{Availability of data and materials}

The data displayed in the present manuscript are available from the corresponding author upon reasonable request.

\section{Authors' contributions}

$\mathrm{JL}$ conducted the experiments and wrote the manuscript. GC, JWL and XZ contributed to the experiments. HC revised 
the manuscript. All authors participated in the design of the study and data analysis. All authors read and approved the manuscript and agree to be accountable for all aspects of the research in ensuring that the accuracy or integrity of any part of the work are appropriately investigated and resolved.

\section{Ethics approval and consent to participate}

All procedures performed in studies involving human participants were approved by the Research Ethics Committee of Henan Provincial People's Hospital, and in accordance with the 1964 Declaration of Helsinki and its later amendments or comparable ethical standards. Informed consent was obtained from all individual participants included in the study. All animal experiments were performed with the approval of the Animal Ethics Committee of Henan Provincial People's Hospital and the procedures for the Care and Use of Laboratory Animals in cancer research.

\section{Patient consent for publication}

Not applicable.

\section{Competing interests}

The authors declare that they have no competing interests.

\section{References}

1. Bray F, Ferlay J, Soerjomataram I, Siegel RL, Torre LA and Jemal A: Global cancer statistics 2018: GLOBOCAN estimates of incidence and mortality worldwide for 36 cancers in 185 countries. CA Cancer J Clin 68: 394-424, 2018.

2. Zheng R, Qu C, Zhang S, Zeng H, Sun K, Gu X and Chen W: Liver cancer incidence and mortality in China: Temporal trends and projections to 2030. Chin J Cancer Res 30: 571-579, 2018.

3. $\mathrm{Fu} \mathrm{J}$ and Wang $\mathrm{H}$ : Precision diagnosis and treatment of liver cancer in China. Cancer Lett 412: 283-288, 2018.

4. Bruix J and Sherman M: Management of hepatocellular carcinoma: An update. Hepatology 53: 1020-1022, 2011.

5. Kudo M, Ueshima K, Kubo S, Sakamoto M, Tanaka M, Ikai I, Furuse J, Murakami T, Kadoya M, Kokudo N, et al: Response evaluation criteria in cancer of the liver (RECICL)(2015 revised version). Hepatol Res 46: 3-9, 2016.

6. Lanza E, Donadon M, Poretti D, Pedicini V, Tramarin M, Roncalli M, Rhee H, Park YN and Torzilli G: Transarteria therapies for hepatocellular carcinoma. Liver Cancer 6: 27-33, 2016.

7. Muz B, de la Puente P, Azab F and Azab AK: The role of hypoxia in cancer progression, angiogenesis, metastasis, and resistance to therapy. Hypoxia (Auck) 3: 83-92, 2015.

8. Eales KL, Hollinshead KE and Tennant DA: Hypoxia and metabolic adaptation of cancer cells. Oncogenesis 5: e190, 2016.

9. Greijer AE and Van der Wall E: The role of hypoxia inducible factor 1 (HIF-1) in hypoxia induced apoptosis. J Clin Pathol 57: 1009-1014, 2004.

10. Liz J and Esteller M: IncRNAs and microRNAs with a role in cancer development. Biochim Biophys Acta 1859: 169-176, 2016.

11. Wong CM, Tsang HC and Ng OL: Non-coding RNAs in hepatocellular carcinoma: molecular functions and pathological implications. Nat Rev Gastroenterol Hepatol 15: 137-151, 2018.

12. Choudhry H, Harris AL and McIntyre A: The tumour hypoxia induced non-coding transcriptome. Mol Aspects Med 47: 35-53, 2016.

13. Chang YN, Zhang K, Hu ZM, Qi HX, Shi ZM, Han XH, Han YW and Hong W: Hypoxia-Regulated lncRNAs in cancer. Gene 575: $1-8,2016$.

14. Liao J, He Q, Li M, Chen Y, Liu Y and Wang J: LncRNA MIAT: Myocardial infarction associated and more. Gene 578: 158-161, 2016.
15. Sun C, Huang L, Li Z, Leng K, Xu Y, Jiang X and Cui Y: Long non-coding RNA MIAT in development and disease: A new player in an old game. J Biomed Sci 25: 23, 2018.

16. Bountali A, Tonge DP and Mourtada-Maarabouni M: RNA sequencing reveals a key role for the long non-coding RNA MIAT in regulating neuroblastoma and glioblastoma cell fate. Int J Biol Macromol 130: 878-891, 2019.

17. Alipoor FJ, Asadi MH and Torkzadeh-Mahani M: MIAT IncRNA is overexpressed in breast cancer and its inhibition triggers senescence and G1 arrest in MCF7 cell line. J Cell Biochem 119: 6470-6481, 2018

18. Xiang Y,Huang Y, Sun H,Pan Y, Wu M and Zhang J: Deregulation of miR-520d-3p promotes hepatocellular carcinoma development via lncRNA MIAT regulation and EPHA2 signaling activation. Biomed Pharmacother 109: 1630-1639, 2019.

19. Jiang Q, Shan K, Qun-Wang X, Zhou RM, Yang H, Liu C, Li YJ, Yao J, Li XM, Shen Y, et al: Long non-coding RNA-MIAT promotes neurovascular remodeling in the eye and brain. Oncotarget 7: 49688-49698, 2016.

20. Petrillo M, Patella F, Pesapane F, Suter MB, Ierardi AM, Angileri SA, Floridi C, de Filippo M and Carrafiello G: Hypoxia and tumor angiogenesis in the era of hepatocellular carcinoma transarterial loco-regional treatments. Future Oncol 14: 2957-2967, 2018

21. Wang Z, Zhao Z, Yang Y, Luo M, Zhang M, Wang X, Liu L, Hou N, Guo Q, Song T, et al: MiR-99b-5p and miR-203a-3p function as tumor suppressors by targeting IGF-1R in gastric cancer. Sci Rep 8: 10119, 2018.

22. Jiang N, Jiang X, Chen Z, Song X, Wu L, Zong D, Song D, Yin L, Wang D, Chen C, et al: MiR-203a-3p suppresses cell proliferation and metastasis through inhibiting LASP1 in nasopharyngeal carcinoma. J Exp Clin Cancer Res 36: 138, 2017.

23. Fang JF, Zhao HP, Wang ZF and Zheng SS: Upregulation of RASAL2 promotes proliferation and metastasis, and is targeted by miR-203 in hepatocellular carcinoma. Mol Med Rep 15: 2720-2726, 2017.

24. Chang JH, Hwang YH, Lee DJ, Kim DH, Park JM, Wu HG and Kim IA: MicroRNA-203 modulates the radiation sensitivity of human malignant glioma cells. Int J Radiat Oncol Biol Phys 94: 412-420, 2016

25. Balamurugan K: HIF-1 at the crossroads of hypoxia, inflammation, and cancer. Int J Cancer 138: 1058-1066, 2016.

26. Masoud GN and Li W: HIF-1 $\alpha$ pathway: Role, regulation and intervention for cancer therapy. Acta Pharmaceutica Sinica B 5: 378-389, 2015.

27. Chen C, Wang J, Liu R and Qian S: RNA interference of hypoxia-inducible factor-1 alpha improves the effects of transcatheter arterial embolization in rat liver tumors. Tumor Biol 33: 1095-1103, 2012

28. Sun X, Jiang H, Jiang X, Tan H, Meng Q, Sun B, Xu R and Krissansen GW: Antisense hypoxia-inducible factor- $1 \alpha$ augments transcatheter arterial embolization in the treatment of hepatocellular carcinomas in rats. Hum Gene Ther 20: 314-324, 2009.

29. Chen CS, Zhao Q, Qian S, Li HL, Guo CY, Zhang W, Yan ZP, Liu R and Wang JH: Ultrasound-guided RNA interference targeting HIF-1 alpha improves the effects of transarterial chemoembolization in rat liver tumors. Onco Targets Ther 8: 3539-3548, 2015.

30. Livak KJ and Schmittgen TD: Analysis of relative gene expression data using real-time quantitative PCR and the $2^{-\triangle \Delta C T}$ method. Methods 25: 402-408, 2001.

31. Phatak P and Donahue JM: Biotinylated micro-RNA pull down assay for identifying miRNA targets. Bio Protoc 7, 2017.

32. Zhou B, Wang J and Yan Z: Ginsenoside Rg3 attenuates hepatoma VEGF overexpression after hepatic artery embolization in an orthotopic transplantation hepatocellular carcinoma rat model. Onco Targets Ther 7: 1945-1954, 2014.

33. Kan Z, Sato M, Ivancev K, Uchida B, Hedgpeth P, Lunderquist A Rosch J and Yamada R: Distribution and effect of iodized poppyseed oil in the liver after hepatic artery embolization: Experimental study in several animal species. Radiology 186: 861-866, 1993.

34. Daher S, Massarwa M, Benson AA and Khoury T: Current and future treatment of hepatocellular carcinoma: An updated comprehensive review. J Clin Transl Hepatol 6: 69-78, 2018.

35. Kumar Y, Sharma P, Bhatt N and Hooda K: Transarterial therapies for hepatocellular carcinoma: A comprehensive review with current updates and future directions. Asian Pac J Cancer Prev 17: 473-478, 2016. 
36. Transarterial chemoembolization in hepatocellular carcinoma treatment: Barcelona clinic liver cancer staging system. World J Gastroenterol 21: 10327-10335, 2015.

37. Rammohan A, Sathyanesan J, Ramaswami S, Lakshmanan A, Senthil-Kumar P, Srinivasan UP, Ramasamy $R$ and Ravichandran P: Embolization of liver tumors: Past, present and future. World J Radiol 4: 405-412, 2012.

38. Vogl TJ, Naguib NN, Nour-Eldin NE, Rao P, Emami AH, Zangos S, Nabil $\mathrm{M}$ and Abdelkader A: Review on transarterial chemoembolization in hepatocellular carcinoma: Palliative, combined, neoadjuvant, bridging, and symptomatic indications. Eur J Radiol 72: 505-516, 2009.

39. Zhang Z, Wang S and Liu W: EMT-Related long non-coding RNA in hepatocellular carcinoma: A study with TCGA database. Biochem Biophys Res Commun 503: 1530-1536, 2018.

40. Huang X, Gao Y, Qin J and Lu S: IncRNA MIAT promotes proliferation and invasion of HCC cells via sponging miR-214. Am J Physiol Gastrointest Liver Physiol 314: G559-G565, 2018.

41. Furuta M, Kozaki KI, Tanaka S, Arii S, Imoto I and Inazawa J: MiR-124 and miR-203 are epigenetically silenced tumor-suppressive microRNAs in hepatocellular carcinoma. Carcinogenesis 31: 766-776, 2009.

42. Ji D, Jiang C, Zhang L, Liang N, Jiang T, Yang B and Liang H: LncRNA CRNDE promotes hepatocellular carcinoma cell proliferation, invasion, and migration through regulating miR-203/ BCAT1 axis. J Cell Physiol 234: 6548-6560, 2019.
43. Luo $\mathrm{D}$, Wang $\mathrm{Z}$, Wu J, Jiang $\mathrm{C}$ and $\mathrm{Wu} \mathrm{J}$ : The role of hypoxia inducible factor-1 in hepatocellular carcinoma. BioMed Res Int 2014: 409272, 2014.

44. Zhang L, Huang G, Li X, Zhang Y, Jiang Y, Shen J, Liu J, Wang Q, Zhu J, Feng X, et al: Hypoxia induces epithelial-mesenchymal transition via activation of SNAI1 by hypoxia-inducible factor-1 $\alpha$ in hepatocellular carcinoma. BMC Cancer 13: 108, 2013.

45. Huang X, Gao Y, Qin J and Lu S: IncRNA MIAT promotes proliferation and invasion of HCC cells via sponging miR-214. Am J Physiol Gastrointest Liver Physiol 314: G559-G565, 2017.

46. Zhao L, Hu K, Cao J, Wang P, Li J, Zeng K, He X, Tu PF, Tong T and Han L: lncRNA miat functions as a ceRNA to upregulate sirt1 by sponging miR-22-3p in HCC cellular senescence. Aging (Albany NY) 11: 7098-7122, 2019.

47. Chen Z,Zuo X, Zhang Y,Han G,Zhang L, Wu J and Wang X: MiR-3662 suppresses hepatocellular carcinoma growth through inhibition of HIF-1 $\alpha$-mediated warburg effect. Cell Death Dis 9: 549, 2018.

48. Xu H, Zhao L, Fang Q, Sun J, Zhang S, Zhan C, Liu S and Zhang Y: MiR-338-3p inhibits hepatocarcinoma cells and sensitizes these cells to sorafenib by targeting hypoxia-induced factor 1 $\alpha$. PLoS One 9: e115565, 2014.

49. Jia XQ, Cheng HQ, Qian X, Bian CX, Shi ZM, Zhang JP Jiang BH and Feng ZQ: Lentivirus-Mediated overexpression of microRNA-199a inhibits cell proliferation of human hepatocellular carcinoma. Cell Biochem Biophys 62: 237-244, 2012. 